


\section{UMA BÚSSOLA PARA OS INVESTIMENTOS}

| POR FERNANDO S. MEIRELLES

\section{As empresas que mais gastam com tecnologia da informação tendem a ser mais lucrativas, mas, para fazer bom uso dos recursos aplicados, é preciso desenvolver indicadores de diagnóstico e gestão de TI.}

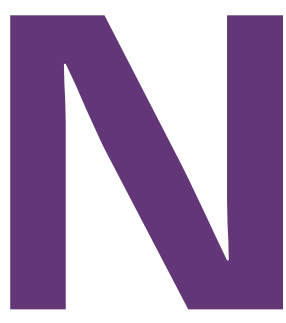

os últimos 30 anos, a Tecnologia da Informação (TI) vem ganhando importância nas empresas. $\mathrm{O}$ gasto e $\mathrm{o}$ investimento com TI passaram de 1,2 para $7,6 \%$ de 1988 a 2016 e devem ultrapassar $8 \%$ do Produto Interno Bruto (PIB) no Brasil em dois ou três anos. Simetricamente, o tamanho do ramo de TI no PIB é também crescente e próximo de $8 \%$.

O papel estratégico que a TI hoje ocupa demanda informações precisas sobre a área. É importante desenvolver indicadores não só para diagnosticar, mas também para administrar, monitorar, comparar, traçar metas, comunicar, alinhar e planejar o uso da TI nas organizações.

Pesquisas do uso de TI nas empresas, como as do Centro de Tecnologia de Informação Aplicada da FGVEAESP (GVcia), do Comitê Gestor da Internet no Brasil (CGI.br) e da consultoria Gartner, geram anualmente muitos indicadores. Vamos revelar dois neste artigo.

\section{ÍNDICE G, O PRIMEIRO INDICADOR}

$\mathrm{O}$ índice mais utilizado calcula o gasto e o investimento total destinado à TI como um percentual do faturamento líquido da empresa. Esse indicador é chamado de Índice G na Pesquisa do GVcia e inclui todas as despesas, as amortizações e o capital investido em TI, incluindo: equipamento, instalações, suprimentos e materiais de consumo, software, serviços, comunicações e custo direto e indireto com pessoal próprio e de terceiros trabalhando em sistemas, suporte e treinamento em TI.

O Índice G depende do porte, do setor ou do ramo da economia e do estágio de informatização da empresa. Quanto mais informatizada for a empresa, maior será o valor do Índice G. Esse é um conceito que não costuma ser facilmente assimilado pelos executivos. Muitos raciocinam que, depois de realizado um vultoso investimento, o índice deveria diminuir - mas não é isso que ocorre. O Índice $G$ cresce conforme a organização avança nos estágios do uso da TI. Assim, uma empresa mais informatizada tem relativamente mais gastos e investimentos com TI.

Considerando os setores econômicos, o Índice G é menor no setor de comércio (menos da metade da média geral de 7,6\%), enquanto atinge maior patamar no setor de serviços, $50 \%$ acima da média. A explicação está, em parte, na estrutura de faturamento, diferente nos dois setores (não é possível comparar, por exemplo, $1 \%$ da receita de 
um supermercado e de um banco), e, em parte, no estágio de informatização. No comércio, a utilização de TI é mais operacional do que em serviços. Este setor inclui os bancos, o ramo da economia que mais gasta e investe em TI (14\%) do faturamento líquido - e no qual a tecnologia tem papel estratégico. Na indústria, o Índice G é, assim como no comércio, inferior à média.

É importante verificar que, em todos os setores, a tendência de gastos é crescente. Para o gestor de TI, o Índice G é útil para acompanhar o comportamento da sua empresa, de empresas similares e a evolução do setor, de forma mais ou menos agregada.

\section{MAIS INVESTIMENTO, MELHOR RESULTADO}

Estudos demonstram que as empresas que mais investem em TI são as mais lucrativas. Por exemplo, pesquisa do GVcia revelou que as indústrias com ações na bolsa que mais investiram em TI, no período de 2001 a 2014, obtiveram maior crescimento da sua receita operacional e resultados operacionais mais eficazes. Para cada $1 \%$ a mais de gastos e investimentos em TI, depois de dois anos, o lucro aumentou $7 \%$.

Ao investigar o impacto da TI no desempenho das empresas brasileiras, descobrimos quatro tipos de comportamento distintos, classificados em conservadores, prudentes, analógicos e digitais. Conforme ilustra o quadro Comportamentos padrão na gestão de TI, as empresas digitais estão no quadrante mais favorável, pois não só investem mais como também conseguem utilizar melhor os recursos investidos. Já as empresas analógicas estão no pior quadrante, pois investem em TI, mas sem utilizar bem os recursos, pois não digitalizaram os negócios. As empresas prudentes, assim como as conservadoras,

\section{OS INDICADORES DE TI EM PRÁTICA \\ I POR JORGE LUIS CORDENONSI}

Em duas empresas globais de diferentes setores em que trabalhei como chief information officer (CIO), foram implantadas abordagens para medir e comunicar o desempenho de TI. No primeiro caso, foi implementado um sistema de informação para automatizar processos operacionais, o que permitiu extrair dados para medir e controlar o desempenho do negócio e, como consequência, o valor agregado da TI. No segundo caso, foi criado um processo para medir os benefícios ao negócio de todos os projetos que envolviam TI. Em ambos, foram necessários: forte disciplina, apoio da alta administração, estruturação de processos, colaboração interdepartamental e garantia de que os indicadores do sistema de medição do valor de TI iriam ser coletados e avaliados de forma sistemática. Eis os casos:

1) Empresa de serviços de alimentação, atuando nas Américas do Sul e Central, tinha duas questões-chave: como administrar e reduzir o custo de matéria-prima e de pessoal nos restaurantes? Como a TI poderia ajudar a empresa a medir e reduzir o custo? Por ter uma operação descentralizada, com restaurantes localizados internamente dentro das empresas-cliente administrados por nutricionistas, o desafio adicional era melhorar o nível de gestão do contrato. A solução adotada foi a implementação de um sistema de gestão dos serviços de alimentação, que contemplava desde a elaboração dos cardápios até o controle diário dos custos. Esse sistema possibilitou o controle e a redução efetiva dos custos. Isso permitiu que a empresa alcançasse melhores margens operacionais, reduzisse o preço dos serviços e, ao mesmo tempo, conseguisse melhor nível de competitividade. Foi desenvolvido um sistema para medir a contribuição de TI para a redução dos custos de operação (matéria-prima e pessoal) do negócio.

2) Empresa da indústria automobilística, com forte presença na América Latina, havia decidido internalizar toda a operação de TI. Era preciso ter um programa bem estruturado e efetivo de projetos que pudesse transferir para dentro da empresa todos os processos que estavam sob a gestão de um provedor de serviços de TI. Como resultado, foi implantada uma nova estrutura global para a área de $\mathrm{Tl}$, com ClOs globais para cada linha de negócio e funções específicas na área. Foram construídos centros de inovação com o objetivo de desenvolver sistemas específicos de acordo com a demanda dos negócios. Foi estabelecido um indicador de desempenho de TI denominado Annual Direct Business Benefit (ADBB), que se tornou o principal parâmetro de avaliação, tanto na aprovação de um projeto quanto na medição do real valor após a implementação.

JORGE LUIS CORDENONSI > Consultor de TI ISG (Information Services Group) > jorge.cordenonsi@fgv.br 


\section{GASTOS E INVESTIMENTOS EM TI COMO PORCENTAGEM DO FATURAMENTO LİQUIDO DAS MÉDIAS E GRANDES EMPRESAS NO BRASIL}

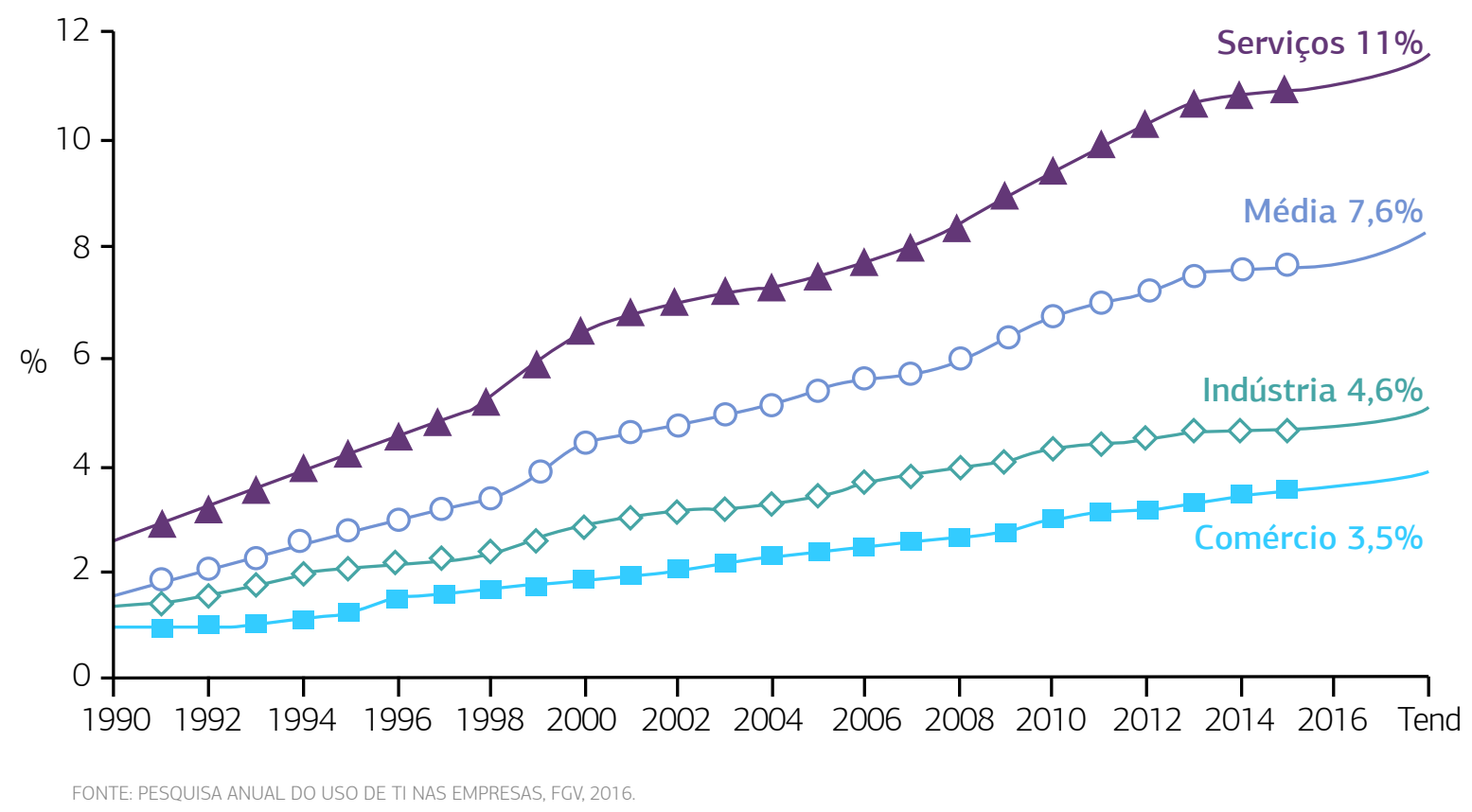

não investem tanto em TI, mas as prudentes conseguem melhor lucratividade, pois usam estrategicamente seus recursos.

Uma tarefa difícil nos estudos sobre retorno da TI é isolar o efeito da TI dos demais itens que afetam os resultados. Assim, podemos afirmar que, na média, as empresas que mais investem em TI são as mais lucrativas, mas não que esse lucro ocorra somente por causa da TI.

O valor da TI para os negócios depende do papel da TI e do nível de informatização ou de maturidade no uso da TI. Os líderes da gestão da TI devem desenvolver métricas de negócios e de TI para comunicar e alinhar as expectativas de como o negócio muda e se beneficia com os gastos com TI. Devem-se utilizar indicadores de fácil compreensão e com a capacidade de permitir comparações (benchmarking) interna e externa.

\section{CUSTO ANUAL DE TI O SEGUNDO INDICADOR}

Um segundo indicador utilizado na prática é o custo anual de TI. Ele pode ser medido de diversas maneiras: por usuário, por teclado, por funcionário ou dividindo o custo anual de TI por outro parâmetro relevante para o negócio da empresa. Como o Índice G, o custo anual de TI varia por segmento de atuação e grau de informatização.

Temos, por exemplo, o Custo Anual de TI por Usuário (CAPU), que é o custo total de TI por ano dividido pelo número de usuários de TI da organização. Sua média foi de R \$ 38.100 em 2015/16 (US\$ 11,4 mil). De forma análoga, considerando o número de dispositivos de TI que a empresas possui, temos o Custo Anual de TI por Teclado (CAPT), de R\$33.300; e o CAPF (custo anual de TI por funcionário) de $\mathrm{R} \$ 32.400$.

Usando métricas de desempenho padrão do setor, podem-se facilitar o entendimento e as comparações com outras organizações similares. Por exemplo, nos hospitais utilizamos o CAPL (custo anual de TI por leito), que resultou em R\$ 120 mil.

As aplicações do modelo de diagnóstico com indicadores demonstram que cerca de dez indicadores selecionados são suficientes para um diagnóstico quantitativo do uso de TI na empresa. Conforme mostram pesquisas, as empresas que utilizam indicadores regularmente superam seus concorrentes em termos de retorno. 


\section{COMPORTAMENTOS PADRÃO NA GESTÃO DE TI}
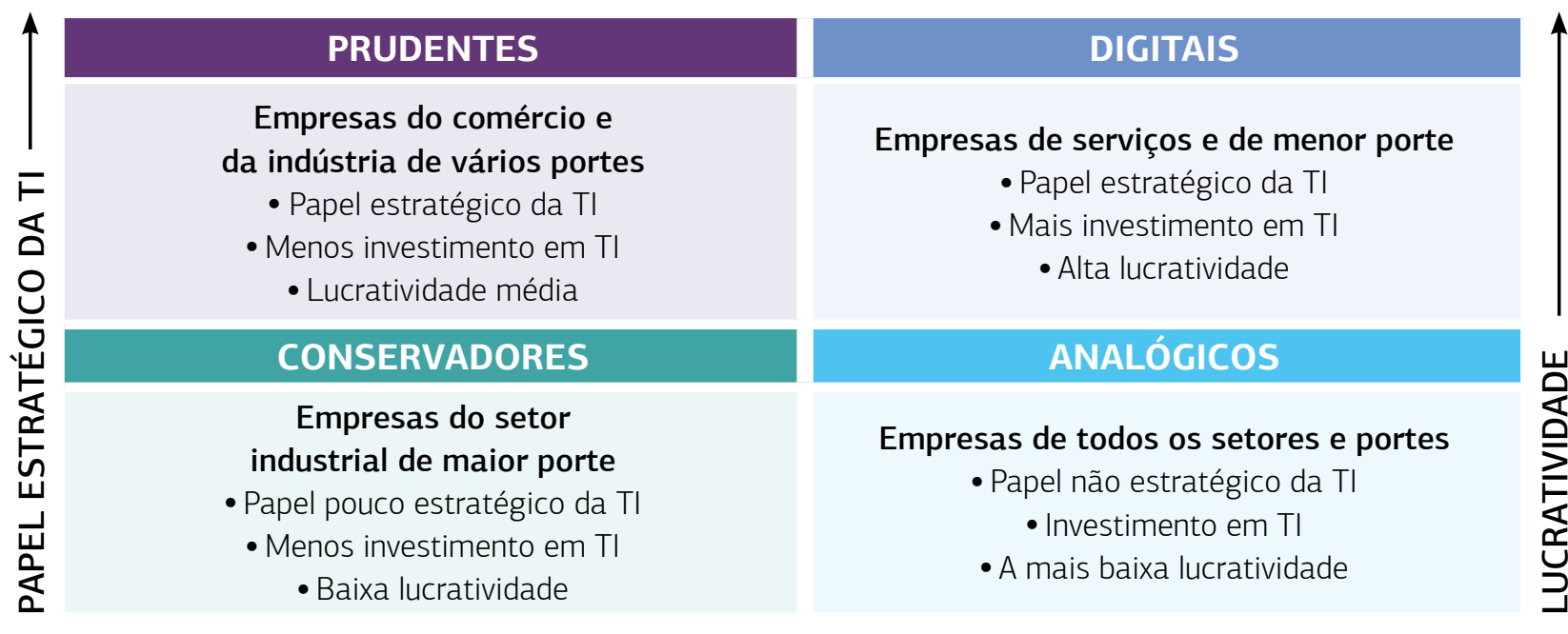

\section{GASTOS E INVESTIMENTOS EM TI}

\section{EVOLUC̣ÃO DE CUSTOS ANUAIS DE TI NO BRASIL*}

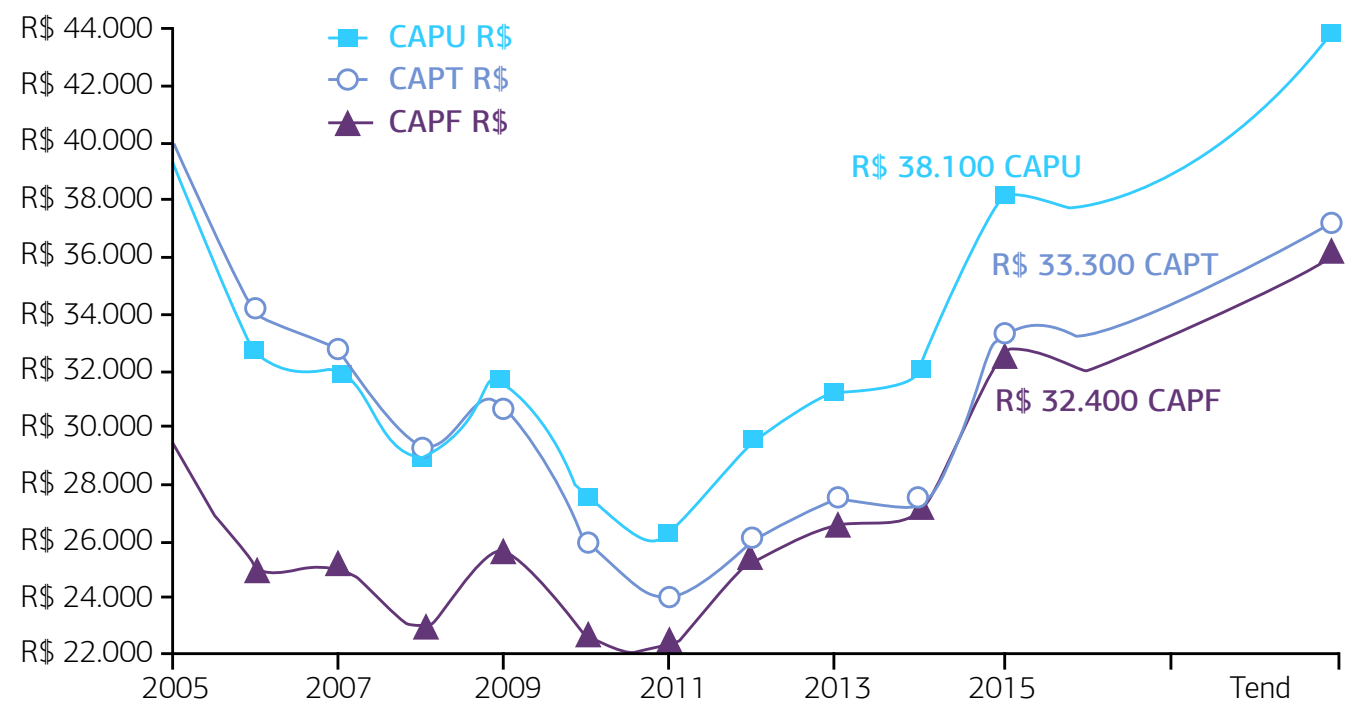

*MÉDIAS E GRANDES EMPRESAS. VALORES EM R\$ DE 2015/16 COM ATUALIZAÇÃO MONETÁRIA; CAPU: CUSTO ANUAL DE TI POR USUÁRIO; CAPT: CUSTO ANUAL DE TI POR TECLADO CAPF: CUSTO ANUAL DE TI POR FUNCIONÁRIO.

FONTE: PESQUISA ANUAL DO USO DE TI NAS EMPRESAS, FCV, 2016.

\footnotetext{
PARA SABER MAIS:

Fernando de Souza Meirelles. Indicadores em pesquisas sobre uso de TIC na gestão das empresas. In: Cgi.br - Comitê Gestor da Internet no Brasil. Pesquisa TIC Empresas. 2017. Disponível em: cetic.br/pesquisa/empresas/publicacoes

Fernando de Souza Meirelles. Pesquisa Anual do Uso de TI nas Empresas. 2016. Disponivel em: fgv.br/cia/pesquisa

Kurt Potter, Sanil Solanki e Ken McGee. Run, Grow and Transform the Business IT Spending: Approaches to Categorization and Interpretation. Gartner, 2016.

Luci Longo e Fernando de Souza Meirelles. Impacto dos Investimentos em Tecnologia de Informação no Desempenho Financeiro das Indústrias Brasileiras. Revista Eletrônica de Administração, v.22, n.1, 2016.

Sanil Solanki. Enhancing and Communicating Performance and Measurement of Business Value of IT. Gartner, 2017.
}

FERNANDO S. MEIRELLES > Professor titular de TI e fundador do GVcia da FGV EAESP > fernando.meirelles@fgv.br 


\section{Primeira revista acadêmica do Brasil especializada na publicação de casos de ensino.}

GVcasos é um periódico eletrônico da FGV/EAESP, lançada por meio de parceria entre a RAE-publicações e o CEDEA - Centro de Desenvolvimento do Ensino e da Aprendizagem.

A missão da GVcasos é fomentar a produção e o uso de casos de ensino em Administração, contribuindo para a disseminação do uso de casos como metodologia de ensino e aprendizagem em nível de graduação, pós-graduação, especialização e educação continuada.

Desde seu lançamento em 2010, a GVcasos publicou mais de sessenta casos em diferentes áreas de Administração: estratégia, marketing, recursos humanos, responsabilidade social e contabilidade. Professores distribuídos em mais de duzentas e cinquenta instituições de ensino localizadas no Brasil e no exterior.

O conteúdo da GVcasos é composto de duas partes:

a) Conteúdo gratuito com acesso livre: casos de ensino nas diversas áreas da Administração, disponíveis para o público em geral.

b) Conteúdo gratuito e restrito a professores: formado pelas notas de ensino dos casos publicados.

A submissão de casos de ensino, acompanhados das respectivas notas de ensino, é aberta a colaboradores de modo geral e deve ser feita pelo sistema online da

\section{GVcasos.}

\section{Acesse para ler e submeter casos de ensino:} FGV.BR/GVCASOS

\section{Central de Relacionamento}

Contatos: + 55(11) 3799-7999 ou 3799-7778

Fax: + 55(11) 3799-7871

gvcasos@fgv.br 